This article is licensed under the Creative Commons Attribution-NonCommercial 4.0 International License (CC BY-NC) (http://www.karger.com/Services/OpenAccessLicense). Usage and distribution for commercial purposes requires written permission.

\title{
Cavernous Hemangioma of the Gallbladder Masquerading as a Carcinoma
}

\author{
Naotake Funamizu Yukio Nakabayashi \\ Department of Digestive Surgery, Kawaguchi Municipal Medical Center, Kawaguchi, Japan
}

\section{Keywords}

Cavernous hemangioma $\cdot$ Gallbladder $\cdot$ Gallbladder tumor

\begin{abstract}
Cavernous hemangioma arising from the gallbladder is extremely rare. Here, we report a cavernous hemangioma of the gallbladder masquerading as a carcinoma. A 75-year-old man was referred to our institution for a follow-up study after gastrectomy. Abdominal computed tomography revealed that the gallbladder was filled with a low-density mass with calcification of the wall. The patient underwent extended cholecystectomy. Histologically, the tumor consisted of vascular endothelial cellular elements and hematomas. The postoperative course was uneventful without complications. Presently, only 7 cases of cavernous hemangioma of the gallbladder have been previously reported. This case serves as an important reminder to consider benign tumors including cavernous hemangioma when investigating all possible causes of a gallbladder tumor.




\section{Case Reports in Gastroenterology}

Case Rep Gastroenterol 2019;13:219-224

DOI: $10.1159 / 000500079$

(c) 2019 The Author(s). Published by S. Karger AG, Basel www.karger.com/crg

Funamizu and Nakabayashi: Cavernous Hemangioma of the Gallbladder Masquerading as a Carcinoma

\section{Introduction}

Cavernous hemangioma $(\mathrm{CH})$ is a congenital venous malformation that occurs in various organs containing vascular components. The most frequent locations of $\mathrm{CHs}$ are the liver and skin, including the face, mouth, and limbs. However, $\mathrm{CH}$ arising from the gallbladder is extremely rare [1]. Thus, we herein report the 8th case of $\mathrm{CH}$ occurring in the gallbladder masquerading as a carcinoma.

\section{Case Report}

Two years after distal gastrectomy for gastric cancer (f Stage IA), a 74-year-old man presented to our institution for a regular follow-up study. A computed tomography (CT) scan of his abdomen revealed a mass in the gallbladder (Fig. 1a). For further investigation, contrastenhanced CT and magnetic resonance imaging (MRI) were performed. The contrast-enhanced CT scan revealed a slightly enhanced region in a low-density area of the gallbladder (Fig. 1b). In addition, the MRI revealed a high-intensity region on T2- and diffusion-weighted images (Fig. 2a, b). Moreover, ultrasonography was performed, but the calcification of the gallbladder wall did not allow taking a clear view. Based on these findings, the patient was diagnosed with a gallbladder carcinoma. Therefore, the patient was admitted to our institute for surgical treatment. The results of the physical examination upon the patient's arrival were as follows: blood pressure, $146 / 86 \mathrm{~mm} \mathrm{Hg}$; heart rate, 82 beats per minute; body temperature, $36.4^{\circ} \mathrm{C}$; body weight, $86.0 \mathrm{~kg}$; and height, $180.0 \mathrm{~cm}$. The physical examination also revealed a lack of tenderness of the entire abdomen. The patient had no specific family or medical history excluding hypertension. Hematologic examination showed a white blood cell count of $4,000 / \mu \mathrm{L}$ (normal range: 3,500-9,000/ $\mu \mathrm{L}$ ), hemoglobin level of $10.8 \mathrm{~g} / \mathrm{dL}$ (normal range: $14.0-16.0$ $\mathrm{g} / \mathrm{dL}$ ), C-reactive protein level of $0.08 \mathrm{mg} / \mathrm{dL}$ (normal: $\leq 0.1 \mathrm{mg} / \mathrm{dL}$ ), carcinoembryonic antigen level of $3.7 \mathrm{ng} / \mathrm{mL}$ (normal: $\leq 5.0 \mathrm{ng} / \mathrm{mL}$ ), and cancer antigen 19-9 level of $13.6 \mathrm{IU} / \mathrm{mL}$ (normal: $\leq 37.0 \mathrm{IU} / \mathrm{mL}$ ). The patient underwent extended cholecystectomy. During the surgery, the gallbladder wall appeared to be hardened and thickened and was strongly adherent to the duodenum, transverse colon, and bile duct. After dissection of the adhesions, the liver bed was resected using the Péan crushing method with a 2-cm margin from the gallbladder. In the resected specimen, the gallbladder was filled with a solid tumor and hematoma, which measured $10.0 \times 8.0 \times 5.5 \mathrm{~cm}$ (Fig. 3). Microscopically, the tumor comprised dilated and closely aggregated vessel components (Fig. 4a). Moreover, CD31 and CD34 staining revealed the presence of vessel components (Fig. 4b, c). The final histopathological diagnosis was $\mathrm{CH}$ of the gallbladder. The postoperative course was uneventful aside from mild ileus, and the patient was discharged 14 days after the surgery. The patient did not experience recurrence for 12 months after the surgery.

\section{Discussion/Conclusion}

The reported prevalence of gallbladder tumors varies from 3 to $7 \%$ in a healthy population [2]. Kwon et al. [3] reported that benign tumors accounted for $88 \%$ of gallbladder tumors. 
The ability to diagnose gallbladder carcinoma has recently improved because of the developments of imaging modalities including CT, MRI, and endoscopic ultrasonography [4]. Recently, Itsuki et al. [5] reported that the diagnostic ability of bile juice cytology through endoscopic transpapillary gallbladder drainage was better than that through endoscopic bile duct drainage. However, there are still no radiological features that can be used to distinguish gallbladder carcinoma from other benign tumors [6]. Therefore, in cases of suspected gallbladder carcinomas, surgeons must perform surgical interventions for gallbladder tumors. To our knowledge, only 8 cases have been reported in the literature, including the present case. The previous reports are summarized in Table 1 [7-13]. Five (63\%) patients had abdominal pain as a chief complaint because of local growth and bleeding of CHs. The median age of the patients was 53 years (range, 11-75 years), and cholecystolithiasis was observed in all cases. Three patients (38\%) were diagnosed with gallbladder carcinomas and underwent surgical procedures. Thus, all patients received an accurate diagnosis of $\mathrm{CH}$ of the gallbladder from surgical intervention, including cholecystectomy and extended cholecystectomy. In conclusion, a $\mathrm{CH}$ arising from the gallbladder has rarely been reported. Therefore, surgical procedures are required to acquire an accurate diagnosis.

\section{Statement of Ethics}

All procedures followed have been performed in accordance with the ethical standards laid down in the 1964 Declaration of Helsinki and its later amendments. Informed consent was obtained from all patients for being included in the study.

\section{Disclosure Statement}

The authors declare that they have no conflict of interest.

\section{Funding Sources}

No funding was received for this study.

\section{Author Contributions}

N.F. wrote the initial draft of the manuscript. N.F. and Y.N. performed the operation. Y.N. contributed to collecting the data and assisted in the preparation of the manuscript. All authors approved the final version of the manuscript. 


\section{Case Reports in Gastroenterology}

Case Rep Gastroenterol 2019;13:219-224

DOI: $10.1159 / 000500079$

(C) 2019 The Author(s). Published by S. Karger AG, Basel www.karger.com/crg

Funamizu and Nakabayashi: Cavernous Hemangioma of the Gallbladder Masquerading as a Carcinoma

\section{References}

1 Lungenschmid D, Schöpf R, Dietze O, Furtschegger A. [Computerized tomography diagnosis of cavernous thymus hemangioma and differentiation from other mediastinal hemangiomas]. Rontgenblatter. 1990 Jul;43(7):301-4.

2 Lee KF, Wong J, Li JC, Lai PB. Polypoid lesions of the gallbladder. Am J Surg. 2004 Aug;188(2):186-90.

3 Kwon W, Jang JY, Lee SE, Hwang DW, Kim SW. Clinicopathologic features of polypoid lesions of the gallbladder and risk factors of gallbladder cancer. J Korean Med Sci. 2009 Jun;24(3):481-7.

4 Leem G, Chung MJ, Park JY, Bang S, Song SY, Chung JB, et al. Clinical value of contrast-enhanced harmonic endoscopic ultrasonography in the differential diagnosis of pancreatic and gallbladder masses. Clin Endosc. 2018 Jan;51(1):80-8.

5 Itsuki H, Serikawa M, Sasaki T, Ishii Y, Tsushima K, Furukawa Y, et al. Indication and Usefulness of Bile Juice Cytology for Diagnosis of Gallbladder Cancer. Gastroenterol Res Pract. 2018 Apr;2018:5410349.

6 Patkar S, Shinde RS, Kurunkar SR, Niyogi D, Shetty NS, Ramadwar M, et al. Radiological diagnosis alone risks overtreatment of benign disease in suspected gallbladder cancer: A word of caution in an era of radical surgery. Indian J Cancer. 2017 Oct-Dec;54(4):681-4.

7 Sewell JH, Miron MA. Benign cavernous hemangioma of the gallbladder. Arch Pathol. 1969 Jul;88(1):30-1.

8 Moffat JH. Cavernous hemangioma of the gallbladder and liver. Can J Surg. 1973 Mar;16(2):172-5.

9 Cabrera OR, Hernández Viruel JA, Colinabarranco M, Villa Fernández A. [Visceral multiple angiomatosis. Clinical case and review of the literature]. Prensa Med Mex. 1977 Jul-Aug;42(7-8):325-30.

10 Jones WP, Keller FS, Odrezin GT, Kelly DR. Venous hemangioma of the gallbladder. Gastrointest Radiol. 1987;12(4):319-21.

11 Furukawa H, Kanai Y, Mukai K, Yamasaki S. Arteriovenous hemangioma of the gallbladder: CT and pathologic findings. AJR Am J Roentgenol. 1997 May;168(5):1383.

12 Mayorga M, Hernando M, Val-Bernal JF. Diffuse expansive cavernous hemangioma of the gallbladder. Gen Diagn Pathol. 1997 Feb;142(3-4):211-5.

13 Crucitti A, La Greca A, Antinori A, Antonacci V, Magistrelli P. Cavernous hemangioma of the gallbladder. Case report and review of the literature. Tumori. 2005 Sep-Oct;91(5):432-5.
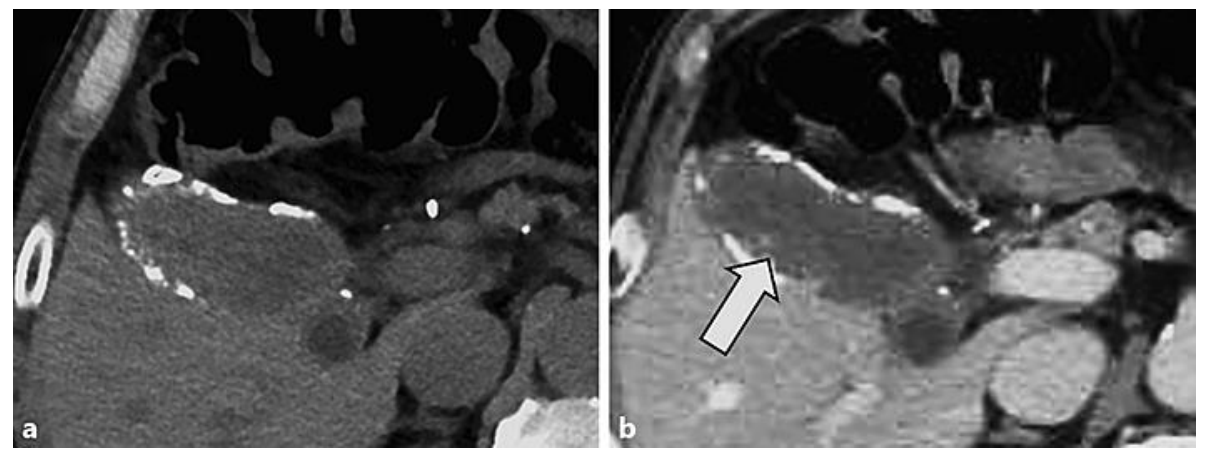

Fig. 1. a Abdominal computed tomography (CT) revealed a low-density mass in the gallbladder. b Abdominal contrast-enhanced CT showed a slightly enhanced region of the tumor in the gallbladder (arrow). 


\section{Case Reports in Gastroenterology}

Case Rep Gastroenterol 2019:13:219-224

(C) 2019 The Author(s). Published by S. Karger AG, Basel www.karger.com/crg

Funamizu and Nakabayashi: Cavernous Hemangioma of the Gallbladder Masquerading as a Carcinoma
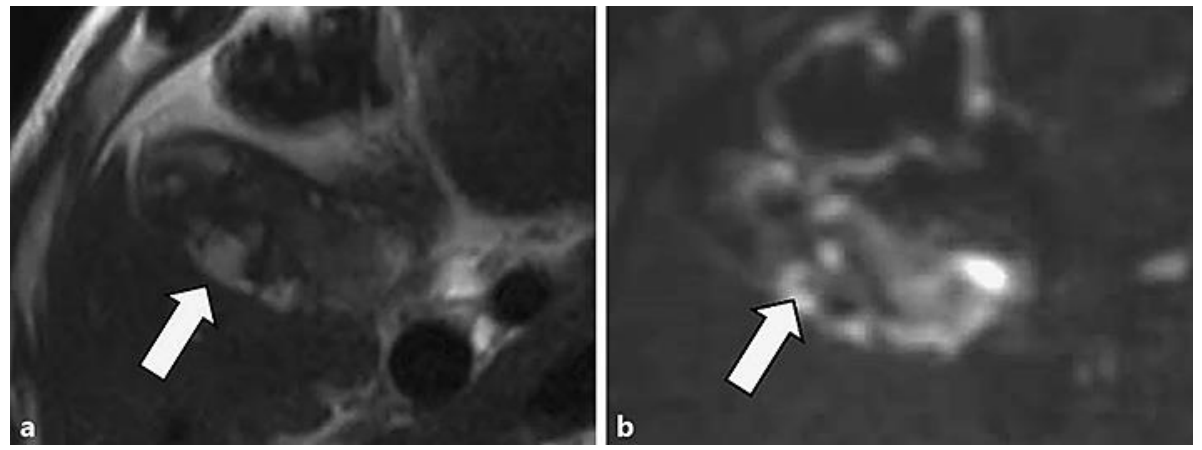

Fig. 2. Magnetic resonance imaging on T2- (a) and diffusion-weighted images (b) showed a high-intensity area in the tumor (arrow).

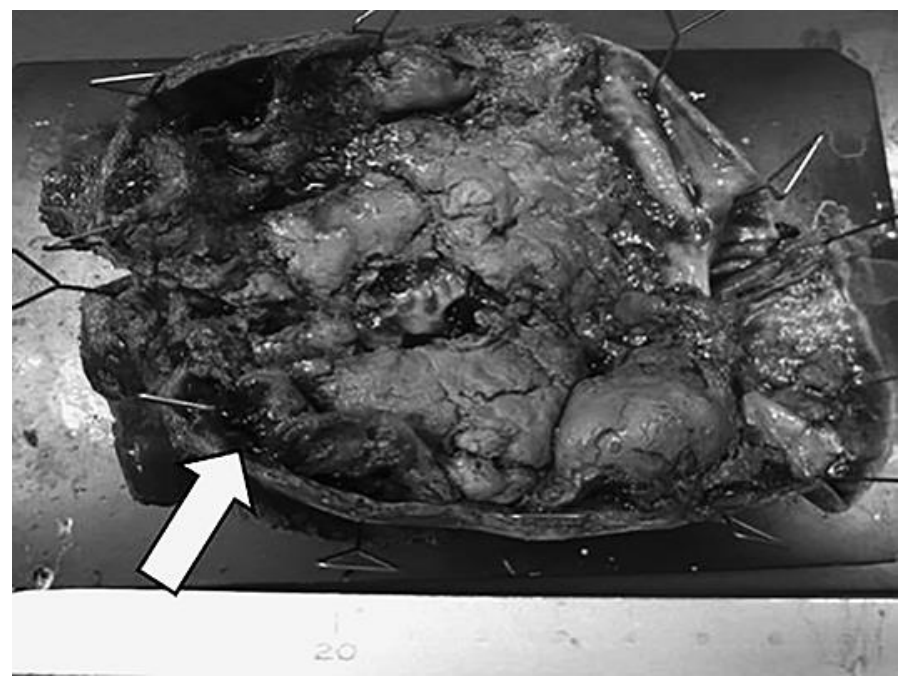

Fig. 3. The resected specimen consisted of a 10-cm solid tumor with hematoma (arrow).
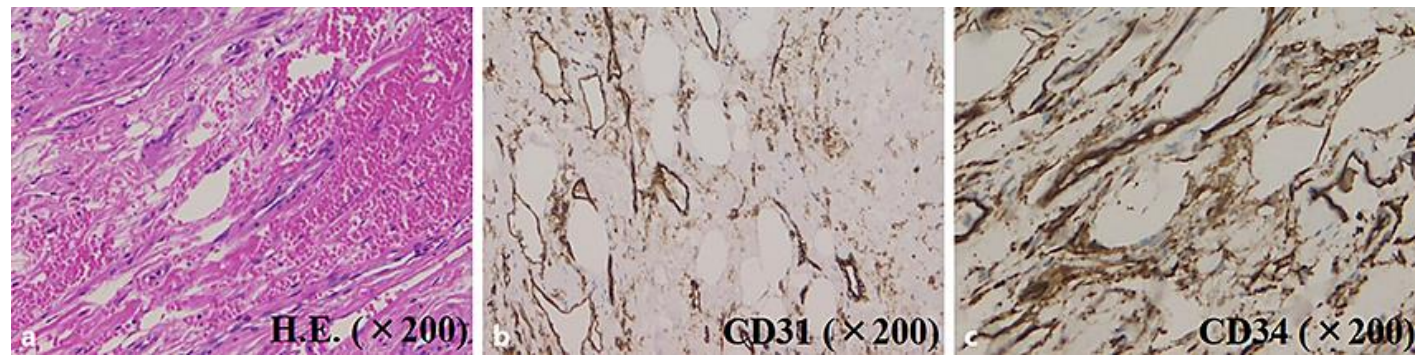

Fig. 4. Hematoxylin and eosin stain (×200 magnification) showed aggregated vessel components (a). CD31 (b) and CD34 (c) staining showed the presence of vessel components. 


\section{Case Reports in Gastroenterology}

(c) 2019 The Author(s). Published by S. Karger AG, Basel www.karger.com/crg

Funamizu and Nakabayashi: Cavernous Hemangioma of the Gallbladder Masquerading as a Carcinoma

Table 1. Previously reported cases of cavernous hemangiomas of the gallbladder

\begin{tabular}{llllllll}
\hline Case & $\begin{array}{l}\text { First author } \\
\text { [ref.] }\end{array}$ & Year & $\begin{array}{l}\text { Age, } \\
\text { years }\end{array}$ & Sex & Symptom & Preoperative diagnosis & Operation methods \\
\hline 1 & Sewell [7] & 1969 & 43 & M & Epigastralgia & Benign tumor & Cholecystectomy \\
2 & Moffat [8] & 1973 & 57 & M & Epigastralgia & Acute cholecystitis & Cholecystectomy \\
3 & Cabrera [9] & 1977 & 62 & M & None & Hepatic angioma & Cholecystectomy \\
4 & Jones [10] & 1987 & 11 & F & Epigastralgia & CH of the liver & Cholecystectomy \\
5 & Furukawa [11] & 1997 & 56 & M & Back pain & Gallbladder carcinoma & Extended cholecystectomy \\
6 & Mayorga [12] & 1997 & 50 & M & Epigastralgia & Mesenteric cyst & Cholecystectomy \\
7 & Crucitti [13] & 2005 & 49 & F & None & Gallbladder carcinoma & Cholecystectomy (L) \\
8 & Present case & 2019 & 75 & M & None & Gallbladder carcinoma & Extended cholecystectomy \\
\hline
\end{tabular}

L, laparoscopy. 